\title{
Targeting dominant publics: How counterpublic commenters align their efforts with mainstream news
}

\section{Florian Toepfl}

Free University of Berlin, Germany

\section{Eunike Piwoni}

University of Goettingen, Germany

\begin{abstract}
This study illustrates how the emphasis structure of counterpublic discourses surfacing online can be predicted by that of the dominant publics that these counterpublicsat the argumentative level-so resolutely oppose. Deploying a single common case study design, the article scrutinizes a counterpublic discourse that surfaced in the comment sections of Germany's opinion-leading news websites in the week after the surprising electoral success of a new anti-Euro party, the Alternative fur Deutschland (AfD). Quantitative content analysis identifies $75 \%$ of all comments posted $(N=2955)$ to all articles about the AfD $(N=19)$ as part of an anti-Euro counterpublic. While this counterpublic sharply opposed the editorial lines of Germany's unanimously pro-common-currency media, it still aligned its efforts closely with this dominant public - albeit at a deeper level. As the findings demonstrate, the frequencies with which commenters adopted six emphasis frames were significantly predicted by the frequencies of these frames in mainstream news.
\end{abstract}

\section{Keywords}

Comment sections, content analysis, counterpublics, Germany, political communication, public sphere 
Recent research has argued that blogs, social networking sites (SNS), and comment sections on news websites are communicative spaces highly conducive to the emergence of counterpublic discourses (Eckert and Chadha, 2013; Jackson and Foucault Welles, 2015, 2016; Renninger, 2015; Toepfl and Piwoni, 2015). Previous studies have demonstrated how the architecture of SNS can support or hamper the surfacing of counterpublic talk (Freelon, 2015; Renninger, 2015), how counterpublic discourses cropping up in the comment sections of news websites can differ depending on the political orientation of the media outlet (Toepfl and Piwoni, 2015), and how Twitter can be used as "a platform to generate and promote counterpublic narratives" (Jackson and Foucault Welles, 2015: 932). Taken together, these studies have thus produced intriguing insights into the dynamics of counterpublic engagement online. Yet, this extant research typically either has not included a systematic empirical analysis of the dominant public (Eckert and Chadha, 2013; Renninger, 2015) or has followed a research logic that focuses exclusively on how dominant publics respond to counterpublic activities (see, for instance, Jackson and Foucault Welles, 2015, 2016). By contrast, this study implements a research design that conceives of counterpublic discourses explicitly as surfacing in response to dominant publics. This change of perspective is important because, as we argue in this article, it is very likely that the shape of counterpublic discourses surfacing in a wide variety of communicative spaces online can be significantly predicted by the shape of the dominant publics to which these counterpublics respond.

The key assumption on which this research design is based is that the more salient a specific aspect of a sensitive issue is in the dominant public, the more frequently that aspect will also be touched upon (i.e. targeted with counter-arguments) by the counterpublic. In order to interrogate this assumption, we draw on De Vreese's (2010) conceptualization of "emphasis frames" (p. 189). According to De Vreese (2010), emphasis frames "suggest that different aspects of an issue can be emphasized"; they are "alternative ways of defining issues" (p. 189). For example, when "thinking about oil drilling, citizens may be presented with [emphasis] frames of reference such as gas prices, unemployment, environment, or US dependency on foreign energy sources" (De Vreese, 2010: 189). Within one and the same emphasis frame, at a second level, different arguments both for and against a specific oil drilling policy can be put forward. We refer to these arguments, in this study, as second-level "argumentative frames." Accordingly, we assume that both mainstream and counterpublic actors may adopt the same emphasis frames (at the first level), while differing diametrically with regard to the argumentative frames put forward within each emphasis frame (at the second level). The empirical analysis presented in this study specifically examines correlations at the first level of emphasis frames. Its key research question is the following: Can the relative frequencies of emphasis frames adopted in a counterpublic discourse be predicted by the frequencies of these frames in the dominant public that this discourse targets?

By raising this question, this study sets out to investigate potential structural commonalities that mainstream publics and counterpublics may share - in sharp contrast to extant research, which has typically focused on discursive power struggles between dominant publics and counterpublics (see, for instance, Eckert and Chadha, 2013; Jackson and Foucault Welles, 2015, 2016). Notably, the causal mechanism presupposed behind the expected co-variations of frames is not that of a straightforward framing or agenda-setting 
"effect" of mainstream mass media content on individuals posting user-generated content (De Vreese, 2010; Tewksbury and Scheufele, 2009). By contrast, adopting the analytical lens of counterpublic theory (Asen, 2000; Fraser, 1990; Warner, 2002), this study presumes an active audience that is critically aware of the fundamental structures of the dominant public and makes intentional decisions to target with greater frequency those emphasis frames that are also deployed with greater frequency in the dominant public. In order to interrogate this line of thinking, we have adopted a single "common case" (Yin, 2014: 52) study design. We have selected for scrutiny a common case of a counterpublic discourse surfacing in a communicative space that invites user-generated content in the immediate vicinity of widely followed mainstream content. As we argue, online spaces configured in this way are particularly conducive for counterpublic collectives with regard to pursuing their outward-oriented goals of engaging with wider audiences (Asen, 2000; Fraser, 1990; Jackson and Foucault Welles, 2015; Warner, 2002).

Specifically, this study analyzes the case of a counterpublic discourse that surfaced in the first week after the surprising electoral success of a new anti-Euro party in the comment sections of Germany's opinion-leading news websites. In the 2013 general elections, the new party, Alternative for Germany (Alternative für Deutschland, AfD) won a stunning $4.7 \%$ of the vote. Only 6 months after its foundation, the party thus failed to clear the $5 \%$ hurdle for entering the German parliament by only a small margin. As we found in a predecessor study (Toepfl and Piwoni, 2015), German mass media discourse about the new party was hegemonic during the first week after the election, in the sense that opinionleading news websites across the political spectrum unanimously framed the new party in ways that were strongly opposed by its supporters (for a description of the consensus structure of the dominant public, see the "Methods" section). By contrast, the overwhelming majority of approximately $75 \%$ of comments appearing on Germany's opinion-leading news websites opposed the mass media's editorial lines, containing some type of counterpublic element that supported the new anti-Euro party (Toepfl and Piwoni, 2015).

Building upon and going beyond Toepfl and Piwoni' (2015) in-depth analysis of the pro-AfD counterpublic, this study juxtaposes two quantitative content analyses grounded in a parallel design, establishing the relative frequencies with which a number of emphasis frames were adopted in (1) the news coverage of the AfD on eight opinion-leading news websites in the first week following the elections ( $N=19$ articles) and (2) all comments posted to these 19 articles $(N=2955)$. Specifically, the study identifies six emphasis frames that were widely adopted in both the dominant and the counterpublic discourse: the party's European Union (EU) policies, its immigration policies, its label, electorate, leadership, and its manifesto. A correlation analysis finds that the relative frequency of a specific emphasis frame in the counterpublic comments that surfaced in a comment section was significantly predicted by both (1) the frequency of this emphasis frame in the individual article above the comment section and (2) the frequency of this emphasis frame in the aggregated mass media coverage of the eight news websites over the course of the entire week. The key assumption formulated above is thus confirmed. Notably, however, the predictive power of the aggregate news coverage during the entire week, in comparison with that of the individual article to which the comments were posted, was found to be considerably stronger. Drawing on counterpublic theory, this result is interpreted as counterpublic commenters being very well aware of the emphasis structure of 
the wider dominant discourse at the time of commenting. As a counterpublic collective, they were apparently targeting not so much the emphasis agenda of the specific article to which they posted their comments, but more the agenda of aggregate mass media coverage around the time of commenting.

In order to flesh out these arguments, the rest of the article is structured as follows. The next section briefly reviews extant research on counterpublics in the digital age. By drawing on this literature, a subsequent section specifies two hypotheses and two research questions to pose regarding the case scrutinized in this study. A further section details the methods of data collection and analysis. This is followed by a section that presents the results. The final section discusses the findings in relation to extant research on counterpublics engaging online and comment sections of news websites as a particular communicative space.

\section{Counterpublics in digital media environments}

In a seminal essay, Nancy Fraser (1990) defined counterpublics as "parallel discursive arenas where members of subordinated social groups invent and circulate counter-discourses, which in turn permit them to formulate oppositional interpretations of their identities, interests, and needs" (p. 67). This classic definition has been taken as a point of departure by most of the recent empirical research in the discipline of communication on counterpublics engaging online (Eckert and Chadha, 2013; Jackson and Foucault Welles, 2015, 2016; Renninger, 2015; Toepfl and Piwoni, 2015). Following Fraser's (1990) theoretical account, counterpublics are typically conceived of as "subaltern" publics that "stand in a contestatory relationship to dominant publics" (Fraser, 1990: 70) or "mainstream publics" (Jackson and Foucault Welles, 2016: 399; Renninger, 2015). Moreover, it is widely acknowledged that the "multiple public sphere" (Asen, 2000: 425) of modern societies is constituted by a plurality of counterpublics and dominant/mainstream publics (Fraser, 1990; Warner, 2002). Dominant publics are understood as being inevitably hegemonic, in the sense that political debates in these arenas are grounded, unavoidably, in consensual patterns that correspond with the views of a society's dominant groups.

With regard to the goals of counterpublic collectives, two types are broadly distinguished in the theoretical literature (Asen, 2000; Fraser, 1990; Dahlberg, 2007, 2011; Warner, 2002):

1. Inward-oriented goals, most importantly, the invention, elaboration, and formulation of alternative identities, interests, and needs, which can be expected to be typically pursued in safe, secluded communicative spaces.

2. Outward-oriented goals, most crucially, the breaking up and shifting of consensus structures within dominant publics by engaging with wider audiences and targeting dominant publics with "counterpublicity" (Asen, 2000: 441). Activities directed toward these outward-oriented goals can be expected to be pursued in communicative spaces that are attended by mainstream audiences, but allow counterpublic-minded individuals to voice and agitate for their ideas.

As extant research indicates differently configured online communicative spaces are conducive to different degrees with regard to these two types of goals. Renninger 
(2015), for instance, has argued that a collective of asexuals chose the particular SNS Tumblr "in order to engage in counterpublic communication unhindered by outsiders" (p. 1524), that is, primarily to pursue inward-oriented goals. By contrast, Jackson and Foucault Welles (2015) have observed a counterpublic discourse that apparently aimed primarily at outward-oriented objectives. Their study illustrates how counterpublic activists hijacked the New York City Police Department's official Twitter hashtag \#myNYPD in order "to organize, generate, and promote counterpublic narratives" (p. 933). In a similar vein, Toepfl and Piwoni (2015) showed that comment sections of news websites, as they are currently configured in many Western democracies, are communicative spaces that provide counterpublic-minded individuals with excellent opportunities to pursue outward-oriented goals.

The latter is the case for at least two reasons. First, in contrast to user-generated content published in discussion forums, blogs, and social networks, comments on news websites appear on mass media websites in the immediate vicinity of journalistic content. Counterpublic statements posted to the comment sections of news websites can thus be assumed to be highly visible to mainstream audiences. Second, in contrast to closely related previous formats such as letters to the editors, the journalists who supervise these spaces typically allow for a wider range of ideas and expressive forms to appear (McCluskey and Hmielowski, 2012). Consequently, even highly emotional and provocative counterpublic statements that fundamentally oppose the normative consensus of a society and its mainstream mass media are likely to appear in comment sections on news websites, as long as their content remains legal according to the media law and the constitution of the respective country.

\section{Developing hypotheses and research questions}

If the key aim of counterpublic collectives engaging in comment sections of news websites is to shift the consensus structure of dominant publics, we can expect that counterpublic commenters will more frequently touch upon those aspects of an issue that also feature more prominently in dominant publics. In order to interrogate this assumption, in this study, we seek to test the predictive power of two slightly differently delimited dominant publics:

1. A dominant public at the article level, which we consider to be constituted by the content of the individual article to which comments were posted.

2. An aggregate level dominant public, which we consider to be represented by the entire coverage of the AfD in all articles published on Germany's opinion-leading news websites about the new party during the week in which the comments were posted.

Accordingly, we specify the following two hypotheses: The relative frequency of an emphasis frame in counterpublic commenting at the bottom of a news article is significantly predicted by the frequency of this emphasis frame

H1. ... in the news article above the comment section (article level dominant public). 
H2. ... in the aggregate coverage of the AfD on Germany's opinion-leading news websites during the entire week (aggregate level dominant public).

In extant research on counterpublics, it is widely acknowledged that "multiple but unequal publics" (Fraser, 1990: 70) participate in the social life of modern societies (Asen, 2000; Dahlberg, 2007, 2011). Yet, to our knowledge, no previous study has empirically investigated how counterpublics interact with two or more differently delimited dominant publics. Against this backdrop, we specify the following research question:

$R Q 1$. Which of the two differently conceived dominant publics predicted the structure of the counterpublic discourse better, that of the individual news article or that of the aggregate news coverage?

Finally, we are also interested in the emerging collective of mainstream commenters, that is, in those comments that supported the dominant public and opposed the counterpublic. Extant literature on online counterpublics has acknowledged but, to our knowledge, not explicitly empirically investigated such subordinate mainstream publics that seek to "contain counterdiscourses" (Asen, 2000: 442). We thus formulate a second research question:

$R Q 2$. Were the frequencies with which emphasis frames were adopted in mainstream comments predicted, similarly, by the frequencies of these frames in the superordinate dominant publics of the individual news article (RQ2a) and the aggregate news coverage (RQ2b)?

\section{Methods of data collection and analysis}

In extant research, in order to delimit the boundaries of counterpublics for empirical analysis, scholars have often relied exclusively on persons, communicative spaces, or topics as "markers of counterpublic status" (Asen, 2000: 426). However, as Asen (2000) has criticized, these "three potential reductions portend unfortunate consequences for studies of a multiple public sphere" (p. 426) because public spheres always emerge as specific constellations of these three elements (see also, Toepfl and Piwoni, 2015). As Asen (2000) has argued, counterpublics are thus "most productively" identified with reference to discursive practices, that is, by using as a key criterion "the [discursive] recognition and articulation of exclusion" (p. 424). Following Asen's (2000) advice, the starting point of this study was the cursory observation of a pro-AfD discourse surfacing in the comment sections of Germany's opinion-leading news websites that powerfully articulated feelings of being excluded by the coverage of these news websites and by German society as such (discursive practices). Based on this observation, the study set out to identify three slightly differently delimited mainstream publics and one counterpublic. In the following, we detail the procedure that we adopted to precisely delimit these four public spheres and, subsequently, to juxtapose their emphasis structures. We have provided additional information in an online supplementary file, which includes a flow chart of the analytical procedure. 


\section{Selection of opinion-leading news websites, articles, and comments}

The time frame considered in this study is the first week after the 2013 German general elections. We chose this period for two reasons. First, during this week, the pro-AfD counterpublic engaged particularly strongly in counterpublicity. Second, the period of one week facilitated the collection of sufficient empirical data for testing our hypotheses by standards of statistical significance. With regard to sampling opinion-leading news websites for analysis, we selected eight major outlets that covered the entire spectrum of mainstream political opinion in Germany. We selected these eight outlets partly on the basis of audience data (Arbeitsgemeinschaft Online Forschung, 2013) and partly on the basis of our cultural knowledge about the centrality of different outlets to the formation of political opinion in Germany (criterion of opinion-leadership; for details on the selection of news websites, consider online supplementary file). Using these criteria, we considered the following selection of news websites: bild.de, faz.net, welt.de, and focus.de (right-leaning); and sueddeutsche.de, spiegel.de, zeit.de, and taz.de (left-leaning). All eight websites are the online versions of highly influential German print-media titles. The selection also includes bild.de as the online version of Germany's only tabloid of national importance (for more details on the selection process, see the online supplementary file). In terms of audience reach (Arbeitsgemeinschaft Online Forschung, 2013), the sample ranked as follows: bild.de (6.59 million unique users per average week in the third quarter of 2013), spiegel.de (5.19), focus.de (3.44), welt.de (3.12), sueddeutsche.de (2.65), zeit.de (1.97), faz.net (1.46), and taz.de (0.42). On these eight websites, we conducted keyword searches for the party's name ("AfD” and "Alternative für Deutschland"). By doing so, we identified in total 19 articles that devoted more than half of their content to the new party. To these 19 articles, 2955 comments were posted, with the number of comments per article ranging from 25 to $495(M=156$, standard deviation $[S D]=128)$.

\section{Measures: six emphasis frames}

In order to scrutinize these 19 news articles and the comments posted beneath them, we adopted a coding procedure that was developed by Toepfl and Piwoni (2015) in order to investigate comment sections of news websites as counterpublic spaces (for details, see the flow chart provided in the online supplementary file). Following this procedure, we began with an in-depth reading of the 19 mainstream news articles as well as a number of approximately 300 randomly selected comments. This in-depth reading was aimed at identifying the most widely used emphasis frames within which the surprising electoral success of the new party was debated in dominant and counterpublic discourse. In a second step, we mapped, within each emphasis frame, the full spectrum of - by definition, diametrically opposedargumentative frames as they were put forward by the dominant public, as opposed to the counterpublic. As a result, we obtained the following six emphasis frames (at the first level), alongside the typical argumentative frames (at the second level), as they were put forward within each emphasis frame by mainstream as opposed to counterpublic writers:

1. Within the first emphasis frame, party label, both journalists and commenters frequently discussed the question of how to label the new party appropriately. In 
mainstream news coverage, the new party was consensually referred to as a "protest," "populist," or "right-wing" party. These were thus key argumentative frames characterizing the consensus structure of the dominant public. By contrast, counterpublic commenters countered these dismissive labels and argued, for instance, that the AfD was a "democratic" party or a "legitimate addition to the party system." The latter are examples of argumentative frames characterizing the consensus structure of the counterpublic.

2. EU policies were the second emphasis frame within which the emergence of the new party was widely debated in both mainstream and counterpublic discourse. At the second level of argumentative frames, mainstream journalists from across the political spectrum agreed that the AfD was hostile toward the EU and that it could only offer simplistic solutions to the Euro crisis. By contrast, counterpublic commenters claimed, for instance, that the AfD was a "pro-European" party whose policies directed at abolishing the Euro were well thought-out and, ultimately, even pro-European.

In a similar manner, the remaining four emphasis frames party leadership, party electorate, immigration policy, and party manifesto were widely deployed in both mainstream and counterpublic discourse. Within these emphasis frames, too, counterpublic and mainstream actors put forward diametrically opposed argumentative frames. Having accomplished this preparatory qualitative analysis, we thus obtained - speaking in the terminology of counterpublic theory (Asen, 2000; Fraser, 1990; Warner, 2002) — a sketch of the consensus structure of a dominant public, as opposed to that of a counterpublic.

Based on these portrayals of the two consensus structures, we then developed a coding scheme and a codebook that facilitated a quantitative analysis of both the 19 news articles and the 2955 comments posted. With regard to comment sections, we used the comment as the smallest unit of data collection $(N=2955)$. With regard to news media coverage, we used the article paragraph $(\mathrm{N}=236)$. We opted for these two units of data collection because they cut the discourse about the AfD in the two disparate communicative spaces (comment sections and news articles) into coherent fragments of approximately the same length (for a similar strategy, consider Papadouka et al., 2016). Using these units of analysis proved to serve well to capture the relative dominance of the six emphasis frames in the 19 articles, as well as in the comment sections beneath.

The coding scheme identified a comment/article paragraph as part of a counterpublic discourse by drawing on three discursive practices widely discussed as characterizing counterpublics (Asen, 2000; Fraser, 1990; Toepfl and Piwoni, 2015; Warner, 2002). It considered a comment or article paragraph as part of a counterpublic if it

1. Argumentatively countered the mainstream consensus within one of the six emphasis frames identified above (argumentative countering; see the examples above), or

2. Strengthened the collective identity of the emerging counterpublic collective by making a statement of personal identification or by employing emotional statements (strengthening identity, for example, "we will win an even bigger share of the vote in the next elections!"), or 
3. Explicitly pointed to firmly consolidated power relationships within the media, politics, or society as allegedly working against the counterpublic (deconstructing power relationships, for example, referring to German public television as "state TV").

Drawing on these three criteria, the coding effort identified 2206 "counterpublic comments" $(74.7 \%)$, understood as comments that featured at least one of the three counterpublic discursive elements. By contrast, only 749 (25.3\%) comments were coded as "mainstream comments," in the sense that they contained none of these elements. Among the counterpublic comments, no more than 79 (3.6\%) were what we called "hybrid counterpublic comments," that is, they simultaneously featured both counterpublic and mainstream elements. In this analysis, we consider these comments part of the counterpublic. We have identified none of the article paragraphs as transporting a counterpublic discursive element. By contrast, comment sections as a communicative space were clearly dominated by a vast majority of counterpublic comments: roughly three out of four comments challenged the dominant public and supported the new party - despite the fact that less than 5\% of the German electorate had voted for the AfD only days before (for an in-depth discussion of these contrasting figures, consider Toepfl and Piwoni, 2015). Importantly, the coding effort, with regard to each news article paragraph and comment, established the presence or absence (1/0) of each of the six emphasis frames. Each comment or article paragraph could thus transport between zero (none) and six (the full range of) emphasis frames. In the following analysis, the emphasis frame functions as the smallest unit of analysis. Table 1 provides an overview of the descriptive statistics of our data set.

To summarize, with regard to the research goals of this study, the key outcome of the coding effort was that it facilitated the precise delimitation of the following four public spheres, as well as the establishment of the relative frequencies of the six emphasis frames within each of them:

1. A counterpublic sphere delimited as all comments containing markers of counterpublic discursive practices posted by commmenters (persons) about the AfD (topic) in the comment sections of Germany's opinion-leading news websites (space).

Table I. Emphasis frames identified in news articles and comment sections: descriptive statistics.

\begin{tabular}{llll}
\hline & $\begin{array}{l}\text { Dominant public } \\
(N=19 \text { articles })\end{array}$ & $\begin{array}{l}\text { Counterpublic } \\
\text { comments }(N=2206 \\
\text { comments })\end{array}$ & $\begin{array}{l}\text { Mainstream } \\
\text { comments }(N=749 \\
\text { comments })\end{array}$ \\
\hline $\begin{array}{l}n \text { (emphasis } \\
\text { frames identified) }\end{array}$ & 284 & 2102 & 598 \\
$\begin{array}{l}\text { Range (per article/ } \\
\text { comment section) }\end{array}$ & 6 to 32 & 12 to 424 & 4 to 106 \\
$\begin{array}{l}M \text { (per article/ } \\
\text { comment section) }\end{array}$ & 14.9 & 110.6 & 31.5 \\
$S D$ & 6.5 & 106.3 & 26.0 \\
\hline
\end{tabular}

SD: standard deviation. 
2. Two dominant publics delimited slightly differently in the mainstream news coverage published about the AfD (topic) by journalists (persons) on Germany's opinion-leading news websites (space). In this news coverage, no paragraphs featuring counterpublic discursive practices were identified.

3. A subordinate mainstream public that sought to discursively "contain" (Asen, 2000: 442) the counterpublic, delimited as all comments containing only mainstream discursive practices posted by AfD-critical users (persons) about the new party (topic) to these comment sections (space).

\section{Coding process and reliability}

After conducting several pilot reliability tests and refining the codebook each time, the two authors of this study, native-German speakers, carried out the coding. A random sample of approximately $30 \%(n=90)$ of article paragraphs and $10 \%(n=319)$ of comments was coded by both coders. With regard to article paragraphs, a reliability test resulted in the following either largely or highly satisfactory percentages of agreement and values for Scott's pi (cf. Neuendorf, 2002: 141-166): party label $(93 \%, \pi=.85)$, party leadership $(98 \%, \pi=.93)$, party electorate $(94 \%, \pi=.87)$, immigration policy $(100 \%, \pi=1)$, EU policy $(97 \%, \pi=.92)$ and party manifesto $(99 \%, \pi=.85)$. With regard to comments, we obtained the following, likewise highly satisfactory results: party label $(94 \%, \pi=.83)$, party leadership $(96 \%, \pi=.81)$, party electorate $(98 \%, \pi=.81)$, immigration policy $(97 \%, \pi=.79)$, EU policy $(95 \%, \pi=.87)$, party manifesto $(99 \%, \pi=.81)$ and counterpublic comment $(96 \%, \pi=.90)$.

\section{Data analysis}

In order to test our hypotheses and answer our research questions, we constructed a data set made up of 114 observations ( 19 articles $\times 6$ emphasis frames). Each of the 114 rows in this data set thus consisted of the relative frequency with which an emphasis frame was adopted: (1) in an article, (2) among the counterpublic comments posted to this article, (3) among the mainstream comments posted to this article, and (4) in the aggregate mass media coverage during the entire week. One row thus established that, for instance, with regard to the frame party label and Article 1, 12.5\% of all frames coded in Article 1 were party label frames ( 2 out of 16$) ; 14.3 \%$ of all frames coded among counterpublic comments posted to this article were party label frames (3 out of 21$) ; 9.2 \%$ of all frames coded among mainstream comments posted to Article 1 were party label frames ( 2 out of 48); and, finally, $27.5 \%$ of all frames coded in the mass media coverage during the entire week of our study were party label frames (78 out of 284). In order to analyze these data, we deployed correlation and multiple regression analyses. Even though our data set can be viewed, from a statistician's perspective, as the population of all articles published and all comments posted in our specific case study, we report inferential statistics, that is, $p$-values and confidence intervals (CIs), at some points of our argument. We do so based on the assumption, frequently adopted in social science research, that such "apparent populations" represent only one "'realization' of some set of social process that could have in principle produced a very large number of other realizations" (Berk et al., 1995: 423). 


\section{Findings}

\section{HI: the emphasis structure of an article predicts counterpublic commenting beneath}

H1 posited that the relative frequency of an emphasis frame in a news article could be deployed to predict the relative frequency of this frame in counterpublic commenting at the bottom of the article. In order to test H1, we computed, within the data set of 114 observations described in the Methods section, Pearson's $r$ for the frequencies of emphasis frames adopted in (1) an individual article and (2) the counterpublic comments appearing at the bottom. We found a moderately strong correlation, $r(112)=.619,95 \%$ bootstrapped CIs, [.463, .749], $p<.01$ (unless otherwise noted, all CIs and $p$-values reported in the following are based on 1000 bootstrap samples). In other words, roughly $38.4 \%$ of the variance of the frequencies with which counterpublic commenters adopted specific emphasis frames could be explained with the frequencies of these frames in the article above (i.e. with the emphasis structure of the dominant public at the article level). This finding supports $\mathrm{H} 1$.

\section{H2: the emphasis structure of aggregate news coverage predicts counterpublic commenting}

In $\mathrm{H} 2$, we similarly assumed that the frequency of an emphasis frame in the aggregate reporting of the eight news websites over the entire post-electoral week could be deployed to predict the frequency of this emphasis frame in counterpublic comments. In order to test H2, we again used our data set of 114 observations. This time, however, we calculated the correlation between (1) the frequency of an emphasis frame in the counterpublic comments at the bottom of each article and (2) the frequency of this frame in the aggregate coverage of news websites. Pearson's $r$ indicated an even stronger correlation than for $\mathrm{H} 1$, with $r(112)=.694,95 \%$ bootstrapped CIs $[.625, .761], p<.01$. Accordingly, $48.2 \%$ of the variance of the frequencies with which counterpublic comments adopted different emphasis frames could be explained with the frequencies of the respective frames in the aggregate news coverage (i.e. with the emphasis structure of the aggregate level dominant public). This finding supports $\mathrm{H} 2$.

\section{$R Q$ I: the predictive power of aggregate news coverage versus the individual article}

RQ1 asked whether a frame's frequency in an individual news article or in aggregate news coverage better predicted the structure of the emerging counterpublic. In order to answer this research question, we ran a multiple regression analysis on our data set of 114 observations, entering two variables as predictors of the frequency of a frame in counterpublic commenting at the bottom of an article (outcome variable): (1) the frequency of this frame in aggregate mass media coverage and (2) the frequency of this frame in the article above the comment section. We found this model to explain $54.9 \%$ $\left(r^{2}\right)$ of the variance of the frequencies with which different emphasis frames were adopted in counterpublic comments, $F(2,111)=67.7, p<.001$. The standardized beta values for 
the two predictors were $.504, p<.001$ for comprehensive mass media coverage and .322 , $p<.001$ for the individual article. We thus can conclude that the predictive power of the aggregate mass media discourse was stronger than that of the individual article, at the bottom of which the counterpublic emerged. Within the analytical framework of counterpublic theory, it can thus be argued that counterpublic commenters aligned their commenting efforts more with the emphasis structure of the aggregate level dominant public than with that of the article level dominant public.

\section{RQ2: predicting the emphasis structure of mainstream commenting}

In RQ2, we asked whether news websites' coverage could be deployed to make similarly valid predictions about the emphasis frames adopted in mainstream comments. To answer this question, we ran a multiple regression analysis on our data set of 114 observations, entering two predictors for the frequency of a frame in mainstream comments (outcome variable): (1) the frequency of this frame in aggregate mass media coverage and (2) the frequency of this frame in the individual article above. We found this model to explain $48.7 \%\left(r^{2}\right)$ of the variance of frames in mainstream commenting, $F(2,111)=52.7, p<.001$. The standardized beta coefficients were $.442, p<.001$ for the frequencies of frames in mass media coverage and $.339, p<.001$ for the frequencies of frames in the individual article. We thus conclude that just like counterpublic commenters, mainstream commenters also aligned their efforts more with the emphasis structure of the aggregate level dominant public than with that of the article level dominant public.

\section{Discussion}

The empirical analysis presented in this study is the first to illustrate how the emphasis structure of dominant publics can be deployed to predict the emphasis structure of counterpublic discourses surfacing online. In order to accomplish this goal, the study juxtaposed two quantitative content analyses, grounded in parallel designs and comparing the relative frequencies of emphasis frames adopted in: (1) the coverage of a new anti-Euro party, the AfD, on Germany's opinion-leading news websites in the first week following the 2013 elections ( $N=19$ articles); and (2) all counterpublic and mainstream comments posted at the bottom of these articles $(N=2955)$. As correlation analyses found, the relative frequencies of the six emphasis frames in counterpublic commenting at the bottom of the 19 articles were significantly predicted by the frequencies of these frames in both (1) the individual article above a comment section (the dominant public at the article level) and (2) the aggregate news coverage of all articles published by the news websites during the entire post-electoral week (the dominant public at the aggregate level). Drawing on counterpublic theory, these empirical findings were interpreted as counterpublic commenters aligning their efforts closely with the underlying emphasis structure of these two differently conceived dominant publics, which commenters - at the argumentative level—so fiercely opposed.

At a more abstract level, this study has assumed that the pro-AfD counterpublic analyzed herein represented a "common case" (Yin, 2014: 52) of a counterpublic discourse surfacing in the comment sections of news websites. Going one step further, we have 
even suggested that similar discursive patterns may be very likely to occur not only in the comment sections of news websites but also in other online spaces that invite user-generated content in the immediate vicinity of widely followed mainstream content. Communicative spaces configured in this specific way may be identified, for instance, in the context of mass media or institutional content posted to platforms like Facebook, Tumblr, YouTube, or Twitter (Jackson and Foucault Welles, 2015). From the perspective of counterpublic theory, such spaces appear to be, just like comment sections on news websites, ideally configured for emergent counterpublic collectives to pursue their outward-oriented goals of engaging with wider audiences and making "counterpublicity" (Asen, 2000: 441). That said, we discuss in the following how this study contributes to primarily two strands of literature: the first investigating the dynamics of counterpublics engaging online, and the second dedicated to comment sections of news websites as a particular communicative space.

\section{Counterpublic collectives engaging online: the predictive power of dominant publics}

From the perspective of the literature on counterpublics engaging online (Cammaerts, 2009; Eckert and Chadha, 2013; Jackson and Foucault Welles, 2015, 2016; Renninger, 2015), the study presented in this article may be considered innovative in primarily four respects. First, as already pointed out in the introduction to the article, unlike previous research (see, for instance, Jackson and Foucault Welles, 2015, 2016), this study has analyzed an online counterpublic discourse explicitly as a response to two differently delimited dominant publics. Second, prior research on counterpublics has typically relied on qualitative methods to investigate the discursive practices in both mainstream and counterpublics (consider, for instance, Cammaerts, 2009; Jackson and Foucault Welles, 2015, 2016; Renninger, 2015). By contrast, the study presented in this article proposes an analytical framework that facilitates quantitative content analysis, and juxtaposition, of discursive practices in mainstream publics and counterpublics. At the core of this analytical framework is the concept of the emphasis frame, within which diametrically opposed argumentative frames are put forward by mainstream and counterpublic speakers (see also Toepfl and Piwoni, 2015).

Third, extant research on online counterpublics has typically focused on the discursive power struggle between dominant publics and counterpublics, while not seeking to identify structural commonalities that mainstream publics and counterpublics share (see, for instance, Eckert and Chadha, 2013; Jackson and Foucault Welles, 2015, 2016). In the terms of the analytical framework proposed in this study, previous research has concentrated on differences between mainstream and counterpublic discourses at the level of argumentative frames, while not attending to potential similarities at the deeper level of emphasis frames. In contrast, this study has interrogated the degree to which mainstream publics and counterpublics co-orient their discursive efforts. Fourth, this study illustrates how both counterpublics and mainstream publics can be neatly delimited for the purposes of empirical analysis as constellations of the three elements of persons, spaces, and topic (Asen, 2000; Toepfl and Piwoni, 2015) by focusing "critical attention [...] on the discursive qualities of counterpublics" (Asen, 2000: 437). Drawing on classic counterpublic 
theory (Dahlberg, 2007, 2011; Fraser, 1990; Warner, 2002), this study suggests conceiving of counterpublic discursive practices as being characterized by one of these three elements: (1) argumentative countering, (2) strengthening identity, and (3) deconstructing power relationships (see also Toepfl and Piwoni, 2015). Implementing these four methodological advancements, the analytical approach proposed in this study has served well to quantitatively scrutinize, and juxtapose, the discursive practices adopted in four differently delimited mainstream publics and counterpublics surfacing online.

\section{Comment sections of news websites: counterpublic theory as an additional interpretive framework}

Comment sections beneath journalistic articles are currently one of the most popular participatory features adopted by news websites across the globe (Hille and Bakker, 2014; Springer et al., 2015; Tenenboim and Cohen, 2015; Weber, 2014). In order to explain differences in the content and intensity of commenting in these spaces, a growing body of research has scrutinized the psychological effects of distinct characteristics of the article, such as its news value (Weber, 2014) or its topic (Tenenboim and Cohen, 2015). It has also analyzed the impact of the discourse architecture of the platform (Freelon, 2015; Hille and Bakker, 2014), that of the political orientation of the news website (Douai and Nofal, 2012; Toepfl and Piwoni, 2015), and that of the different types of "gratifications sought" by the users (Springer et al., 2015: 800). Moreover, a relatively limited number of studies has investigated the transfer of content elements-be they news frames, issues, or topics - from news coverage to comment sections, and vice versa, typically drawing on different variants of agenda-setting or intermedia agendasetting theory (Martin, 2014; Muñiz et al., 2015; Papadouka et al., 2016). To summarize, while research on comment sections of news websites has adopted a wide variety of theoretical perspectives, counterpublic theory has rarely been deployed to make sense of the content surfacing in this specifically configured communicative space (for an exception, consider Toepfl and Piwoni, 2015).

However, as the findings of this study illustrate, an analytical approach grounded in counterpublic theory can perform excellently in explaining discursive patterns observed in this communicative space. In this study, specifically, a counterpublic approach has allowed for the formulation of two hypotheses ( $\mathrm{H} 1$ and $\mathrm{H} 2$ ), which have served well in predicting the emphasis structure of the discourse about the AfD cropping up in the comment sections of Germany's opinion-leading news websites. At a more abstract level, one might even argue that in cases where an "emergent collective" (Asen, 2000: 438) feels excluded by democratic mainstream media, a counterpublic interpretive framework might be better poised than other explanatory models, such as framing effects or agendasetting theories, with regard to predicting the content of comments cropping up beneath journalistic articles (McCombs, 2014; Tewksbury and Scheufele, 2009). In our study, for instance, we could also have interpreted the correlation between the frequencies of an emphasis frame in an individual article and in the comment sections beneath it (H1) as a straightforward framing or second-level agenda-setting effect of journalistic content on individual commenters (as did, for instance, Muñiz et al., 2015; Papadouka et al., 2016). We observed not only a significant degree of correlation between the potential cause and 
its effect. In addition, the presumed cause (the frequency of an emphasis frame in a news article) also consistently preceded the presumed effect (the frequency of this emphasis frame in the comments posted at the bottom) in time (the condition of "time order," McCombs, 2014: 15).

The assumption of such a short-term media effect of news content on commenters, however, is challenged by our subsequent finding that the frequencies of frames in comment sections were even better predicted by their respective frequencies in the aggregate news websites' coverage during the entire week (RQ1). The empirical evidence of this study is thus even more in line with a theoretical framework grounded in counterpublic thinking, according to which an active audience aligns its commenting efforts more with the emphasis structure of a wider aggregate dominant public than with that of a more narrowly conceived article level dominant public. In addition, models assuming a media effect of journalistic content on commenters typically conceive of commenters as individuals. By contrast, the approach of this study explicitly imagines commenters acting as collectives of critically aware citizens pushing for social change. As extant research has shown, discourses surfacing online on topics that touch upon the interests of emergent counterpublic collectives function frequently according to this second logic: They are penetrated by calls for collective action, criticism of unequal power relationships, and the collective pursuit of common discursive strategies and political aims (Jackson and Foucault Welles, 2015, 2016; Renninger, 2015; Toepfl and Piwoni, 2015). Within the pro-AfD counterpublic discourse scrutinized in this study, for instance, approximately $64 \%$ of comments contained elements aimed at strengthening the identity of the emergent counterpublic collective, and 38\% transported elements that deconstructed dominant power relationships as working against the counterpublic collective.

\section{Pathways for future research: exploring how populist counterpublics engage online}

This study has limitations, many of which, however, point toward fascinating avenues for future research. First of all, the study has been grounded in the analysis of a single case (Yin, 2014). In order to replicate and substantiate the findings presented in this article, future research needs to scrutinize more similar cases, that is, cases of counterpublic discourses that surface online in the immediate vicinity of mainstream content. Future research of this type could extend data collection by exploring the predictive power of a wide range of differently delimited dominant publics. It could explore the dynamics of how the emphasis structures of mainstream publics and counterpublics shift over time, and it could conduct in-depth interviews with users in order to investigate why mainstream and counterpublic commenters refrain from using some emphasis frames-and decide to deploy others. Second, previous research has typically focused on counterpublic collectives, as they can be broadly associated with left-leaning or progressive political goals (Dahlberg, 2011; Eckert and Chadha, 2013; Jackson and Foucault Welles, 2015, 2016; Renninger, 2015; for an exception, consider Cammaerts, 2009). However, as Fraser (1990) has argued, not all "subaltern counterpublics are always necessarily virtuous" (p. 67). Given the recent rise of radical right-wing, populist, and nationalist political forces across the globe, it appears politically highly relevant to scrutinize the counter-discourses 
that these collectives produce. In this regard, a first novel aspect that has not featured centrally in extant theorizing on counterpublics (Asen, 2000; Dahlberg, 2007, 2011; Fraser, 1990; Warner, 2002) may be the role of state-sponsored counterpublic discourses, as they are produced, for instance, by the collectives of commenters hired by Russia's ruling elites to publish counter-discourses in the comment sections of Western news media (Khazan, 2013). A second novel aspect may be the peculiar controversies around the nature of "truth" and "facts" that have emerged in the context of these movements, resulting in Oxford Dictionaries declaring "post-truth" the word of the year in 2016. Why, how, and with what consequences do such "anti-democratic and anti-egalitarian" (Fraser, 1990: 67) counterpublics engage in different communicative spaces online? Generating academic knowledge that addresses these questions will be crucial in order to confront the complex challenges that these - not necessarily virtuous - counterpublics pose to Western democracies.

\section{Funding}

The author(s) disclosed receipt of the following financial support for the research, authorship, and/ or publication of this article: This research was supported by an Emmy Noether research grant sponsored by the German Research Foundation DFG.

\section{References}

Arbeitsgemeinschaft Online Forschung (2013) Internet facts 2013. Available at: https://www.agof. de/download/Downloads_Internet_Facts/Downloads_Internet_Facts_2013/Downloads Internet_Facts_2013-09/09-2013\%20ranking_angebote_woche_if2013_09.xlsx?x69376

Asen R (2000) Seeking the "counter" in counterpublics. Communication Theory 10(4): 424-446.

Berk RA, Western B and Weiss RE (1995) Statistical inference for apparent populations. Sociological Methodology 25: 421-458.

Cammaerts B (2009) Radical pluralism and free speech in online public spaces: the case of North Belgian extreme right discourses. International Journal of Cultural Studies 12(6): 555-575.

Dahlberg L (2007) Rethinking the fragmentation of the cyberpublic: from consensus to contestation. New Media \& Society 9(5): 827-847.

Dahlberg L (2011) Re-constructing digital democracy: an outline of four "positions." New Media \& Society 13(6): 855-872.

De Vreese CH (2010) Framing the economy: effects of journalistic news frames. In: D'Angelo P and Kuypers JA (eds) Doing News Framing Analysis. New York: Routledge, pp. 187-214.

Douai A and Nofal HK (2012) Commenting in the online Arab public sphere: debating the Swiss minaret ban and the "Ground Zero mosque" online. Journal of Computer-mediated Communication 17(3): 266-282.

Eckert S and Chadha K (2013) Muslim bloggers in Germany: an emerging counterpublic. Media, Culture \& Society 35(8): 926-942.

Fraser N (1990) Rethinking the public sphere: a contribution to the critique of actually existing democracy. Social Text 25-26: 56-80.

Freelon D (2015) Discourse architecture, ideology, and democratic norms in online political discussion. New Media \& Society 17(5): 772-791.

Hille S and Bakker P (2014) Engaging the social news user: comments on news sites and Facebook. Journalism Practice 8(5): 563-572.

Jackson SJ and Foucault Welles B (2015) Hijacking \#myNYPD: social media dissent and networked counterpublics. Journal of Communication 65(6): 932-952. 
Jackson SJ and Foucault Welles B (2016) \#Ferguson is everywhere: initiators in emerging counterpublic networks. Information, Communication \& Society 19(3): 397-418.

Khazan O (2013) Russia's online-comment propaganda army. The Atlantic. Available at: http:// www.theatlantic.com/international/archive/2013/10/russias-online-comment-propagandaarmy/280432/

McCluskey M and Hmielowski J (2012) Opinion expression during social conflict: comparing online reader comments and letters to the editor. Journalism 13(3): 303-319.

McCombs M (2014) Setting the Agenda: The Mass Media and Public Opinion. Cambridge: Polity Press.

Martin JA (2014) Agenda setting, elections, and the impact of information technology. In: Johnson TJ (ed.) Agenda Setting in a 2.0 World: New Agendas in Communication. New York: Routledge, pp. 28-52.

Muñiz C, Alvídrez S and Téllez N (2015) Shaping the online public debate: the relationship between the news framing of the expropriation of YPF and readers' comments. International Journal of Communication 9: 3245-3263.

Neuendorf KA (2002) The Content Analysis Guidebook. London: Sage.

Papadouka ME, Evangelopoulos N and Ignatow G (2016) Agenda setting and active audiences in online coverage of human trafficking. Information, Communication \& Society 19(5): 655-672.

Renninger BJ (2015) "Where I can be myself ... where I can speak my mind": networked counterpublics in a polymedia environment. New Media \& Society 17(9): 1513-1529.

Springer N, Engelmann I and Pfaffinger C (2015) User comments: motives and inhibitors to write and read. Information, Communication \& Society 18(7): 798-815.

Tenenboim $\mathrm{O}$ and Cohen AA (2015) What prompts users to click and comment: a longitudinal study of online news. Journalism 16(2): 198-217.

Tewksbury D and Scheufele DA (2009) News framing theory and research. In: Bryant J and Oliver MB (eds) Media Effects: Advances in Theory and Research. New York: Routledge, pp. 17-33.

Toepfl F and Piwoni E (2015) Public spheres in interaction: comment sections of news websites as counterpublic spaces. Journal of Communication 65(3): 465-488.

Warner M (2002) Publics and counterpublics. Public Culture 14(1): 49-90.

Weber P (2014) Discussions in the comments section: factors influencing participation and interactivity in online newspapers' reader comments. New Media \& Society 16(6): 941-957.

Yin RK (2014) Case Study Research: Design and Methods. Los Angeles, CA: SAGE.

\section{Author biographies}

Florian Toepfl heads a research group on "Mediating (Semi-)Authoritarianism: The Power of the Internet in the Post-Soviet Region" at the Free University of Berlin. His research focuses on the inter-relations between media and politics in authoritarian regimes, as well as on nationalist and populist counterpublics in democratic contexts.

Eunike Piwoni is a lecturer (Akademische Rätin) at the Institute for Sociology, Georg-AugustUniversität Göttingen. Her current research interests include the sociology of cosmopolitanism, public and counterpublic discourse (specifically in relation to debates on immigrant integration), and the sociology of emotions. 